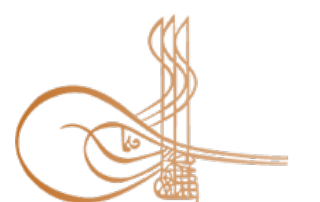

www.turkishstudies.net/social
Turkish Studies - Social Sciences

eISSN: 2667-5617

Research Article / Araștırma Makalesi

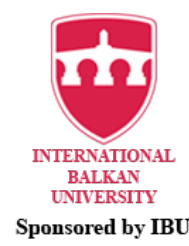

Sponsored by IBU

\title{
Serbest Zaman Yolu İle Stresle Baş Edebilme Stratejilerinin İncelenmesi: Halı Sahada Futbol Oynayanlar Üzerinde Bir Araştırma
}

\author{
The Examination of the Strategies to Cope with Stress Via Free Time: \\ A Research on Those Playing Football on Astro Pitch
}

Meliha Uzun* - Osman İmamoğlu**

\begin{abstract}
In this study, it is aimed to examine the strategies of coping with stress on carpet Pitch soccer players. A total of 462 people playing soccer on the carpet pitches were filled up with the "Strategy for Coping with Stress through Leisure Time before the matches. Independent t-test in paired comparisons and one-way analysis of variance (ANOVA) in multiple comparisons and LSD tests were used to determine the difference. A statistically significant difference was found in the leisure strategy subscales and total score according to the age category of the players $(\mathrm{p}<0.05)$. The scores in the third age category are lower. In leisure friendship, the scores of 20-24 and 25-29 age groups are higher than in the 30-35 age group in case of Temporary Coping and Mood improvement. No statistically significant difference was found in the scale scores of those who were within normal health limits and those who were obese according to their history of active sports and body mass index $(p>0.05)$. A significant difference was found in all subscales and total scale scores in comparison of leisure strategy subscale and total scores according to income and marital status $(\mathrm{p}<0.05)$. When the total score is examined; It was determined that the average of the people with good income status was significantly higher than the average of those with low and very good income level. There is a significant difference in favor of single people according to marital status variable in friendship, temporary coping, mood improvement subevaluation and total score. It was concluded that the strategies of coping with stress on carpet soccer pitch players changed according to age category, income and marital status and did not change according to body weight. Soccer players can be given explanatory information about coping with stress and improving their mood.
\end{abstract}

Structured Abstract: Introduction and Purpose: Stress is a part of modern life by people who can influence different effects of modern life and seek ways to cope with it (Shields, 2003). Leisure activities provide psychological support in coping with stress, believing in the benefits of dealing with and managing stress (Iwasaki et al., 2005). In this study, it is aimed to examine the strategies of coping with stress on carpet Pitch

\footnotetext{
* Dr. Öğr. Üyesi, Şırnak Üniversitesi, Beden Eğitimi ve Spor Yüksekokulu, Antrenörlük Eğitimi Bölümü Asst. Prof. Dr., Sirnak University, High School of Physical Educaiton and Sport, Coaching Education Department ORCID 0000-0002-1691-3504

melihauzunn16@gmail.com

** Prof. Dr., Ondokuz Mayıs Üniversitesi, Spor Bilimleri Fakültesi, Spor Yöneticiliği Bölümü

Prof. Dr., Ondokuz Mayis University, Faculty of Sport Sciences, Department of Sport Management

ORCID 0000-0001-6671-6042

osmani55@hotmail.com

Cite as/ Atıf: Uzun, M., İmamoğlu, O. (2020). Serbest Zaman yolu ile stresle baş edebilme stratejilerinin incelenmesi: halı sahada futbol oynayanlar üzerinde bir araştırma. Turkish Studies - Social, 15(4), 2187-2198. https://dx.doi.org/10.29228/TurkishStudies.42974

Received/Geliș: 19 April/Nisan 2020

Accepted/Kabul: 20 June/Haziran 2020

Copyright $($ INTAC LTD, Turkey

Checked by plagiarism software

Published/Yaym: 25 June/Haziran 2020

CC BY-NC 4.0
} 
soccer players. It is thought that leisure strategies will change according to age category, active sports in the past, income and marital status.

\section{Method:}

Study group: A total of 462 males between the ages of 20-35 playing soccer in the carpet fields in Samsun province are the participants. Some of the participants are those who have been doing sports in the past. In addition to personal information, the "Strategy Scale for Coping with Stress by Leisure Time" was filled before the matches. Fully filled surveys are taken into consideration.

Scale: "Coping Stress Strategy Scale" which was developed by Iwasaki and Mannell (1999) and was first validated and trusted by Bedir (2016) and then Cevik et al. (2018). The questionnaire was applied as 7point Likert Type Scale. Definitely disagree 1, disagree 2, partially disagree 3, indecisive 4, partially agree 5, agree 6 and strongly agree 7. The Turkish version of the questionnaire was specified by Bedir (2016) in 18 items. The scale consists of three sub-dimensions. These are leisure companionship (items 2, 5, 7, 8, 15, 18), temporary coping (items $3,4,9,11,14,17)$, and leisure mood enhancement sub-dimension $(1,6,10,12,13$, 16th items). Cevik et al. (2018), 15th article of leisure friendship and 12th and 13th articles of mood were removed and calculations were made with 15 questions. In this study, evaluation was made on 15 items. Among the sub-dimensions of the Leisure Strategy Scale, leisure time friendship internal consistency coefficient is 0.88 , leisure coping coefficient internal consistency coefficient is 0.87 and leisure mood increase is 0.86 . Cronbach Alpha coefficient of the overall scale was 0.93 .

Statistics: Independent t-test in paired comparisons and one-way analysis of variance (ANOVA) in multiple comparisons and LSD tests were used to determine the difference.

Results: According to the age category, the average length of the participants in the study varied between 173.09-175.06 cm. Mean body weights are between $73.72-79.37 \mathrm{~kg}$. He reported that the body mass index for athletes was normal at $25 \mathrm{~kg} / \mathrm{m}^{2}$. In this study, the body weights of the 30-35 age group were above normal limits. In this study, the average score of the friendship sub-dimension was 23.08 points, the average score of the temporary coping sub-dimension was 29.36 points, the average score of the mood enhancement sub-dimension was 18.10 points and the total average score was 68.19 points. A statistically significant difference was found in the leisure strategy subscales and total score according to the age category of the players $(p<0.05)$. The scores in the third age category are lower. In leisure friendship, the scores of $20-24$ and 25-29 age groups are higher than in the 30-35 age group in case of Temporary Coping and Mood improvement. No statistically significant difference was found in the scale scores of those who were within normal health limits and those who were obese according to their history of active sports and body mass index ( $>0.05)$. A significant difference was found in all subscales and total scale scores in comparison of leisure strategy subscale and total scores according to income and marital status $(\mathrm{p}<0.05)$. When comparing leisure strategy subscale and total scores according to marital status, a statistically significant difference was found between subscale and total scale scores $(\mathrm{p}<0.05)$. Those who are single have higher scores than those who are married. This situation may also be attributed to the married people's feeling of responsibility towards their families. It is thought that those who have good income have better strategies to cope with stress through leisure time. It is thought that being healthy and obese according to body weight does not have an impact on the strategy of coping with stress through leisure time. Conclusion: It was concluded that the strategies of coping with stress on carpet soccer pitch players changed according to age category, income and marital status and did not change according to body weight. Soccer players can be given explanatory information about coping with stress and improving their mood. Not only football players but also business owners should take precautions to eliminate free time barriers.

Keywords: Free Time, Astro Pitch, Football, Football Player, Mood, Stress

Öz: Bu çalışmada halı sahalarda futbol oynayanların serbest zaman yolu ile stresle baş edebilme stratejilerinin incelenmesi amaçlanmıştır. Halı sahalarda futbol oynayan toplam 462 kişiye "Boş Zaman Yolu ile Stresle Baş Etme Strateji Ölçeği" maçlardan önce doldurtulmuştur. İstatistiksel işlemlerde bağımsız t- testi ve tek yönlü varyans analizi (ANOVA) ve farklılık tespiti içinde LSD testleri uygulanmıştır. Futbolcuların yaş kategorisine göre boş zaman stratejisi alt ölçekler ve toplam puanda istatistiksel olarak anlamlı farklılık bulunmuştur $(\mathrm{p}<0,05)$. Üçüncü yaş kategorisindekilerin puanları daha düşüktür. Boş zaman arkadaşlığında, geçici baş 
edebilme ve ruh halini iyileştirme durumunda 20-24 ve 25-29 yaş gruplarının puanları 30-35 yaş grubuna göre daha yüksektir. Geçmişinde aktif spor yapma durumuna göre ve beden kütle indeksine göre normal sağlıklı olma sınırları içerisinde bulunanlar ile obez bulunanların ölçek puanlarında istatistiksel olarak anlamlı farklılık bulunmamıştır $(\mathrm{p}>0,05)$. Gelir ve medeni duruma göre boş zaman stratejisi alt ölçek ve toplam puanları karşılaştırılmasında tüm alt ölçeklerde ve toplam ölçek puanda anlamlı farklılık bulunmuştur $(\mathrm{p}<0,05)$. Toplam puan incelendiğinde; gelir durumu iyi olan kişilerin ortalaması, düşük ve çok iyi gelir düzeyine sahip olanların ortalamasından anlamlı şekilde yüksek olduğu tespit edilmiştir. Boş zaman yolu ile stresle baş etme strateji ölçeği, arkadaşlık, geçici baş edebilme, ruh hali iyileştirme alt boyutları ile toplam puanda medeni durum değişkenine göre bekar kişiler lehinde anlamlı bir farklılık görülmektedir. Halı sahalarda futbol oynayanların boş zaman yolu ile stresle baş edebilme stratejileri yaş kategorisi, gelir ve medeni duruma göre değiştiği ve vücut ağırlığına göre ise değişmediği sonucuna varılmıştır. Halı sahalarda futbol oynayanlara serbest zaman yolu ile stresle baş edebilme ve ruh halini iyileştirebilme konularında açıklayıcı bilgiler verilebilir.

Anahtar Kelimeler: Serbest Zaman, Halı Saha, Futbol, Futbolcu, Ruh Hali, Stres

\section{Giriş}

Hayatın içerisinde yer alan stres kavramı genellikle olumsuz bir durum olarak algılanır (Kızıldağ, 2018). Stres, yaşamın farklı alanlarında insanı etkisi altına alabilen ve insanlar tarafindan modern yaşamın bir parçası haline dönüştürüldügüü bir kavramdır (Shields, 2003).

Stres insanları psikolojik yönden olumsuz olarak etkileyen sorunlardan biri olarak görülür. Stresle başa çıkabilmek için ferd kendi açısından stres yaratan olaylara karşı direnç gösterir. $\mathrm{Bu}$ olaylara karşı göstermiş olduğu duygusal, bilişsel ve hareketsel tepkilerin tamamı stres olarak ifade edilir (Folkman ve Moskowitz, 2004). Genel olarak stresin insanlar üstünde psikolojik bir etki yarattığı bilinse de, aynı zamanda bağışıklık sistemi ve sinir sistemi üzerinde de birçok fizyolojik etkiye sahip olduğu belirtilmektedir (Aldwin, 2014). Stresle baş etmede stresten uzaklaşma durumunu sağlamanın yanı sıra, strese sebep olan problemlerinde yönetilmesi etkili olmaktadır (Iwasaki ve diğ., 2005). Baş etme stratejileri kişilerde olumsuzluğa (stres ve kaygıya) sebep olan içsel ya da dışsal etkenlere karşı koymak için onların geliştirdiği yöntemler olarak görülebilir (Doğan ve Yalçın, 2019). İnsanlar bu stres durumundan kurtulmalıdırlar. Duygu inançları; insanların hangi duyguları yaşayabilecekleri, değiştirebilecekleri veya düzenleyecekleri hakkındaki değerlendirmelerini ifade eder (Goodman ve diğ., 2020). İnsanlar sağlıklarını korumaları ve psikolojik olumsuzluklardan uzaklaşmaları için serbest zamanlarını iyi bir şekilde değerlendirmelidirler (Aksoy, 2020). Serbest zaman ile stresle baş etme arasında yakın bir ilişki vardır (Iwasaki, 2006). Farklı serbest zaman aktiviteleri ile uğraşma, serbest zamana ilişkin spor katılımı, sosyalleşme imkanı sağlayan serbest zaman aktiviteleri, açık alan ve doğada yapılan serbest zaman aktiviteleri stresi azaltabilir (Çevik ve diğ., 2018). Fiziksel aktivite kişinin fiziksel, psikolojik ve duygusal sağlığını iyileştirmesi için iyi bir yoldur. Dahası, düzenli fiziksel aktivite ve sağlıklı bir yaşam tarzı, insanların kendilerini daha iyi hissetmelerine ve kilolarını korumalarına yardımcı olurken, sağlık üzerinde önemli bir etkiye sahiptir (Taşmektepligil ve diğ., 2013; Atan ve diğ., 2012). Uzmanlar, egzersiz ve fiziksel değerlendirmenin yaşam kalitesinde önemli bir rol oynadığını belirtmişlerdir (Ayyıldız ve diğ., 2019). İlaveten, sporun kişilik gelişiminden serbest zaman değerlendirilmesine kadar bir çok konuda olumlu etkisinin olduğu belirtilmektedir (Koca ve diğ., 2018).

Serbest (boş) zaman insan hayatının özel bir alanıdır. Seçme şans1, yaratıcılık, hoşnutluk ve memnuniyet içerir. Aktivite kavramı çoğunlukla fiziksel, buna ek olarak entelektüel kişilik, sosyal, görüntü ve ruhsal olayların çok yönlü durumlarını içerir (Ağılönü, 2007; Kabadayı ve diğ., 2017). Serbest zaman kavramı ferdin hem kendisi hem de başkaları için bütün zorunluluklardan ya da bağlantılardan kurtulduğu ve kendi isteğiyle bir faaliyet ile uğraşacağı zamandır. İlaveten, ferdin çalışmadığı, hayat zorunluluklarının ve resmi sorumluluklarının dışında kendi isteği ile geçirdiği zaman olarak ifade edilir (K1lbaş, 1995). İnsanlar günümüzde serbest zaman faaliyeti olarak daha 
fazla seçenek ve tercih ile karşı karşıyadırlar (Kır, 2007; Atan ve diğ., 2016). Serbest zaman, ruhsal baskıdan kurtulmak, kısıtlama durumlarından serbestliğe geçmek, iş sonrası geriye kalan zaman bölümü, zorunlu görevler yapıldıktan sonra artan zaman bölümü gibi kavramlarla açıklanabilir. Serbest zamana sahip olan fertlerin rekreasyon ve rekreatif faaliyetler ile uğraşma imkanı vardır. Serbest zamanların ve boş zamanları değerlendirmenin önemi, fertlerin dinlenme ve eğlenme ihtiyaçlarını karşılama ve onların hayatla bağlarını kuvvetlendirerek mutlu hale getirmiş olmasındadır (Bedir, 2016; Kaya, 2003). Serbest zaman kavramı, günümüzde çağdaş sanayi toplumunun yapısal bir özelliğini ve bu toplum şeklinin bir ürününü oluşturur (Karaküçük, 2014).

Serbest zamanlar maddi bir gelir kazanma kaygısı düşünmeden, iş yapan üzerindeki stresi ortadan kaldırması, onu rahatlatması ve her yaştaki insanın serbest zamanlarında arkadaşlarıyla bir arada olabilmeleri gibi firsatları doğurur. Çeşitli aktiviteler ile günlük iş yükü stresinden belli bir zaman olsun kaçış sağlayarak fertlerin yeni bilgileri, becerilere sahip olmaları için uygun ortamı hazırlayarak daha sağlıklı bir durumda yaşama devam etmelerine de imkan sağlar (Davis ve diğ., 1991). Serbest zaman değerlendirme, kişilerin zorunlu ihtiyaçları dışında kalan boş zamanlarında haz ve doyum kazanmak amacıyla çeşitli aktivitelerden herhangi birine ya da birçoğuna istekli olarak katılması halidir (Gülbahçe, 1996). Boş zaman arkadaşlığı; bireylerin serbest zamanlarında yapmış oldukları rekreasyonel faaliyetleri aracılığılyla edindikleri arkadaşlıkları ifade etmektedir (Bedir ve diğ., 2016). İnsanların özüne uygun ve yaparken mutlu oldukları çeşitli etkinliklere katılarak gündelik yaşamın monotonluğundan sıyrılması ve diğer bireylerle bütünleşerek toplumsal bir kişilik kazanması olarak ifade edilen serbest zamanı değerlendirme aslında hediye özelliği taşıyan fakat gelir amacı taşımayan, özü gereği sosyal özellikteki faaliyetler olarak açıklanır (Bedir, 2016). Serbest zaman aktiviteleri olumlu ruh halini artırmak olumsuz ruh halini azaltmak için firsatlar sunar (Endler ve Parker, 1990). Aynı zamanda, bu aktiviteler stresle baş etme ve stresi yönetmeye olan faydasına ilişkin inanma ile stresle baş etmede psikolojik bir destek oluşturur (Iwasaki ve diğ., 2005). Zamanı iyi değerlendirebilen fertler her an ne yapacağını bilirler. Zamanını en iyi kullanır ve amaçladığı hedeflere göre zamanını dizayn eder (Alay ve Koçak, 2003). Serbest zaman faaliyetlerine katılım, kişilerin yaşama şekillerine, özelliklerine ve zaman kullanımlarına göre farklılık gösterir. Yaptığı faaliyetlerin türü, katılma şekilleri ve bunlara ayırdıkları zaman pek çok durumdan etkilenir. Irk, din, toplumsal ve kişisel özellikler, yaş, cinsiyet gibi pek çok faktör bu kapsamda sayılabilir (Tolukan, 2010). Bedir ve diğg. (2016) tarafından spor bilimleri fakültesinde okuyan öğrencilerin boş zaman yolu ile stresle baş etme durumu üzerine yapılan bir çalışma olmasına karşın, araştırmanın boş zaman yoluyla stresle baş etme hususunda kuramsal yapısını ölçme yetisine ilişkin soru işaretleri olmasından dolayı, yeni araştırmalara ihtiyaç duyulduğu ifade edilebilir. Zaman yönetiminin olduğu bir yerde boş zamanın varlığından bahsedecek olursak boş zamanı doğru ve verimli bir şekilde yönetmek gereklidir (Kirtepe ve Uğurlu, 2018).

$\mathrm{Bu}$ bağlamda çalışmada, rekreatif amaçlı olarak halı sahalarda futbol oynayanların serbest zaman yolu ile stresle baş edebilme stratejilerinin incelenmesi amaçlanmıştır. Stresle baş etme konusunda etkili olan etmenlerin belirlenmesiyle halı sahalarda futbol oynanma oranının artacağ 1 düşünülmektedir. Halı sahalarda futbol oynayanlarda serbest zaman stratejilerinin yaş kategorisine, geçmişte aktif spor yapma durumuna, gelir ve medeni durumuna göre değişeceği düşünülmektedir.

\section{Yöntem}

Araştırmada çalışma grubunu, Samsun ilinde halı sahalarda futbol oynayan, 20-35 yaş aralığında bulunan toplam 462 erkek oluşturmaktadır. Katılımcıların bir kısmı geçmişte de spor yapmakta olanlardır. Futbolculara kişisel bilgileri tanımlamaya yönelik sorular ile "Boş Zaman Yolu ile Stresle Baş Etme Strateji Ölçeği” maçlardan önce doldurtulmuştur. Tam doldurulan anketler değerlendirmeye alınmıştır. 


\section{Boş Zaman Yolu ile Stresle Baş Etme Strateji Ölçeği}

Iwasaki ve Mannell (1999) tarafindan geliştirilen ve önce Bedir (2016) tarafindan ve sonra Çevik ve diğ. (2018) tarafından geçerlilik ve güvenirliği yapılan "Boş Zaman Yolu ile Stresle Baş Etme Strateji Ölçeği” ile bilgi toplanmıştır. Anket 7’li (Likert Tipi) Ölçek şeklinde uygulanmıştır. Kesinlikle katılmıyorum 1, katılmıyorum 2, kısmen katılmıyorum 3, kararsızım 4, kısmen katılıyorum 5, katılıyorum 6 ve kesinlikle katılıyorum 7 şeklinde puanlanır. Anketin Türkçe sürümü Bedir (2016) tarafindan toplam 18 madde olarak belirtilmiştir. Ölçek üç alt boyuttan oluşmuştur. Bunlar "boş zaman arkadaşlı̆̆ı" (2, 5, 7, 8, 15, 18. maddeler), "boş zaman geçici baş edebilme" (3, $4,9,11,14,17$. maddeler) ve "boş zaman ruh hali artırma" alt boyutu $(1,6,10,12,13,16$. maddeler) olarak belirtilmiştir. Çevik ve diğ. (2018) tarafindan boş zaman arkadaşlığ 15. maddesi ile ruh hali 12. ve 13. maddeler çıkartılarak 15 soru ile hesaplamalar yapılmıştır. Bu çalışmada da 15 madde üzerinden değerlendirme yapılmıştır. Uygulanılan boş zaman strateji ölçeği alt boyutlarından boş zaman arkadaşlığ 1 iç tutarlılık katsayısı 0,88 ; boş zaman geçici baş edebilme iç tutarlılık katsayısı 0,87 ve boş zaman ruh hali artırma katsayısı 0,86 'dir. Genel ölçeğin cronbach alpha katsayısı 0,93 olarak hesaplanmıştır.

\section{BKİ (Beden Kütle İndeksi) = Vücut ağırlı̆̆ $(\mathrm{kg}) /$ boy $(\mathrm{m})^{2}=\mathrm{kg} / \mathrm{m}^{2}$ \\ İstatistiksel ișlemler}

Verilerin analizi SPSS 23,0 paket programı ile gerçekleştirilmiştir. Normal olup olmama durumuna Kolmogorov-Smirnov testi ile bakılmıştır. Elde edilen verilerin normal dağılım gösterdiği tespit edilmiştir. Değerlendirmede ikili mukayeseler için Bağımsız örneklem t-testi kullanılırken, ikiden fazla olan grupların karşılaş̧ırmaları için Tek Yönlü Varyans Analizi yapılımıştır. Ayrıca üçlü gruplarda farklılığa neden olan grubun tespitinde LSD testi kullanılmıştır. Bu çalışmada anlamlılık düzeyi 0,05 olarak kabul edilmiştir.

\section{Bulgular}

Tablo 1: Yaş kategorisine göre katılımcıların boy uzunluğu ve ağırlıklarının karşılaştırılması

\begin{tabular}{|c|c|c|c|c|c|c|}
\hline$n=462$ & Yaş kategori & $\mathbf{N}$ & Ort. & SS & F/LSD & $\mathbf{p}$ \\
\hline \multirow{4}{*}{$\begin{array}{l}\text { Boy uzunluğu } \\
(\mathrm{cm})\end{array}$} & 1. Grup (20-24 yaşlar ) & 47 & 173,09 & 5,51 & \multirow[t]{4}{*}{2,87} & \multirow[t]{4}{*}{0,058} \\
\hline & 2.Grup (25-29 yaşlar) & 144 & 173,35 & 9,39 & & \\
\hline & 3.Grup (30-35 yaşlar) & 271 & 175,06 & 7,34 & & \\
\hline & Toplam & 462 & 174,00 & 7,92 & & \\
\hline \multirow{4}{*}{$\begin{array}{l}\text { Vücut ağırlığ1 } \\
(\mathrm{kg})\end{array}$} & 1. Grup (20-24 yaşlar ) & 47 & 73,72 & 8,78 & \multirow{4}{*}{$\begin{array}{c}10,38 * * \\
3>1,2\end{array}$} & \multirow[t]{4}{*}{0,000} \\
\hline & 2.Grup (25-29 yaşlar) & 144 & 75,97 & 9,80 & & \\
\hline & 3.Grup (30-35 yaşlar) & 271 & 79,37 & 9,72 & & \\
\hline & Toplam & 462 & 77,74 & 9,85 & & \\
\hline \multirow{4}{*}{$\begin{array}{l}\text { Beden kütle } \\
\text { indeksi }\left(\mathrm{kg} / \mathrm{m}^{2}\right)\end{array}$} & 1. Grup (20-24 yaşlar ) & 47 & 24,57 & 2,36 & \multirow{4}{*}{$\begin{array}{c}5,07^{*} \\
3>1\end{array}$} & \multirow[t]{4}{*}{0,007} \\
\hline & 2. Grup (25-29 yașlar) & 144 & 25,33 & 3,05 & & \\
\hline & 3.Grup (30-35 yaşlar) & 271 & 25,91 & 2,91 & & \\
\hline & Toplam & 462 & 25,59 & 2,93 & & \\
\hline
\end{tabular}

$* \mathbf{p}<0,05 * * \mathbf{p}<0,001$

Yaş kategorisine göre katılımcıların boy uzunlukları arasında istatistiksel olarak önemli bir farklılık yok iken $(\mathrm{p}>0,05)$; vücut ağırlıkları ve beden kütle indeksleri arasında istatistiksel olarak önemli farklılık bulunmuştur ( $<<0,05$ ve $p<0,001$ ). LSD testi sonuçlarına göre; boş zaman yolu ile stresle baş etme strateji ölçeği vücut ağırlığında 30-35 yaşın ortalaması 20-24 ile 25-29 yaşın ortalamalarından anlamlı şekilde yüksek bulunmuştur. Ayrıca beden kütle indeksinde 30-35 yaşın ortalaması 20-24 yaşın ortalamasından anlamlı şekilde yüksek tespit edilmiştir. 
Tablo 2: Yaş kategorisine göre boş zaman stratejisi puanlarının karşılaştırılması

\begin{tabular}{|c|c|c|c|c|c|c|}
\hline$n=462$ & Yaş kategori & $\mathbf{N}$ & Ort. & SS & F/LSD & p \\
\hline \multirow[t]{4}{*}{ Arkadaşlık } & 1. Grup (20-24 yaşlar ) & 47 & 24,83 & 8,13 & $4,00^{*}$ & 0,019 \\
\hline & 2.Grup (25-29 yaşlar) & 144 & 24,36 & 9,27 & $1,2>3$ & \\
\hline & 3.Grup (30-35 yaşlar) & 271 & 22,10 & 8,92 & & \\
\hline & Toplam & 462 & 23,08 & 9,01 & & \\
\hline \multirow{4}{*}{$\begin{array}{l}\text { Geçici baş } \\
\text { edebilme }\end{array}$} & 1. Grup (20-24 yaşlar ) & 47 & 29,13 & 9,00 & $3,97 *$ & $\mathbf{0 , 0 2 0}$ \\
\hline & 2.Grup (25-29 yaşlar) & 144 & 28,26 & 10,32 & $3<1,2$ & \\
\hline & 3.Grup (30-35 yaşlar) & 271 & 25,84 & 10,13 & & \\
\hline & Toplam & 462 & 26,93 & 10,15 & & \\
\hline \multirow{4}{*}{$\begin{array}{l}\text { Ruh halini } \\
\text { iyileştirme }\end{array}$} & 1. Grup (20-24 yaşlar ) & 47 & 19,13 & 7,25 & $4,17 *$ & 0,013 \\
\hline & 2.Grup (25-29 yaşlar) & 144 & 19,43 & 7,19 & $2>3$ & \\
\hline & 3.Grup (30-35 yașlar) & 271 & 17,35 & 7,14 & & \\
\hline & Toplam & 462 & 18,18 & 7,22 & & \\
\hline \multirow[t]{4}{*}{ Toplam puan } & 1. Grup (20-24 yaşlar ) & 47 & 73,09 & 23,64 & $4,20 *$ & 0,016 \\
\hline & 2.Grup (25-29 yașlar) & 144 & 72,06 & 26,36 & $1,2>3$ & \\
\hline & 3.Grup (30-35 yaşlar) & 271 & 65,28 & 25,73 & & \\
\hline & Toplam & 462 & 68,19 & 25,91 & & \\
\hline
\end{tabular}

p $<0,05$

Yaş kategorisine göre boş zaman stratejisi toplam puanlanı karşılaştırılmasında 20-24 yaş grubu ve 25-29 yaş grubunun toplam puanları 30-35 yaş grubundan önemli derecede yüksek bulunmuştur $(\mathrm{p}<0,05)$. LSD testi sonuçlarına göre; boş zaman yolu ile stresle baş etme strateji ölçeği arkadaşlık alt boyutunda 20-24 ile 25-29 yaşın ortalamaları, 30-35 yaşın ortalamasından anlamlı şekilde yüksek bulunmuştur. Geçici baş edebilme alt boyutunda; 30-35 yaşın ortalaması 20-24 ile 25-29 yaşın ortalamalarından anlamlı şekilde düşük olduğu gözlenmiş̧tir. Ruh halini iyileştirme alt boyutunda; 25-29 yaşın ortalaması 30-35 yaşın ortalamasından yüksektir. Toplam puan incelendiğinde ise; 20-24 ile 25-29 yaş ortalamalarının 30-35 yaşın ortalamasından anlamlı şekilde yüksek olduğu saptanmıştır.

Tablo 3: Geçmişte aktif spor yapma durumuna göre boş zaman stratejisi puanlarının karşılaştırılması

\begin{tabular}{|c|c|c|c|c|c|c|}
\hline$n=462$ & Spor yapma durumu & $\mathbf{N}$ & Ort. & SS & t- testi & $\mathbf{p}$ \\
\hline \multirow[t]{2}{*}{ Arkadaşlık } & Spor yapan & 228 & 23,26 & 8,93 & \multirow[t]{2}{*}{0,42} & \multirow[t]{2}{*}{0,674} \\
\hline & Spor yapmayan & 234 & 22,91 & 9,11 & & \\
\hline \multirow{2}{*}{$\begin{array}{l}\text { Geçici baş } \\
\text { edebilme }\end{array}$} & Spor yapan & 228 & 27,82 & 10,04 & \multirow[t]{2}{*}{1,860} & \multirow[t]{2}{*}{0,64} \\
\hline & Spor yapmayan & 234 & 26,06 & 10,20 & & \\
\hline \multirow{2}{*}{$\begin{array}{l}\text { Ruh hali } \\
\text { iyileştirme }\end{array}$} & Spor yapan & 228 & 18,28 & 7,18 & \multirow[t]{2}{*}{0,297} & \multirow[t]{2}{*}{0,767} \\
\hline & Spor yapmayan & 234 & 18,08 & 7,28 & & \\
\hline \multirow[t]{2}{*}{ Toplam puan } & Spor yapan & 228 & 69,36 & 25,58 & \multirow[t]{2}{*}{0,956} & \multirow[t]{2}{*}{0,340} \\
\hline & Spor yapmayan & 234 & 67,05 & 26,23 & & \\
\hline
\end{tabular}

Geçmişte aktif spor yapma durumuna göre boş zaman stratejisi alt ölçek ve toplam puanları karşılaştırılmasında önemli bir farklılık tespiti olmamıştır $(\mathrm{p}>0,05)$.

Tablo 4: Beden kütle indeksi kategorisine göre boş zaman stratejisi puanlarının karşılaştırılması

\begin{tabular}{|c|c|c|c|c|c|c|}
\hline$n=462$ & BKİ & $\mathbf{N}$ & Ort. & $\mathbf{S S}$ & $t$-testi & p \\
\hline \multirow{2}{*}{ Arkadaşlık } & $20-24,99 \mathrm{~kg} / \mathrm{m}^{2}$ & 230 & 22,63 & 9,22 & \multirow[t]{2}{*}{$-1,05$} & \multirow[t]{2}{*}{0,291} \\
\hline & $25-38 \mathrm{~kg} / \mathrm{m}^{2}$ & 232 & 23,52 & 8,80 & & \\
\hline \multirow{3}{*}{$\begin{array}{l}\text { Geçici baş } \\
\text { edebilme }\end{array}$} & $20-24,99 \mathrm{~kg} / \mathrm{m}^{2}$ & 230 & 26,30 & 10,42 & \multirow[t]{2}{*}{$-1,32$} & \multirow[t]{2}{*}{0,181} \\
\hline & $25-38 \mathrm{~kg} / \mathrm{m}^{2}$ & 232 & 27,55 & 9,85 & & \\
\hline & $20-24,99 \mathrm{~kg} / \mathrm{m}^{2}$ & 230 & 17,81 & 7,43 & $-1,08$ & 0,278 \\
\hline
\end{tabular}




\begin{tabular}{lllllll}
\hline $\begin{array}{l}\text { Ruh hali } \\
\text { iyileştirme }\end{array}$ & $25-38 \mathrm{~kg} / \mathrm{m}^{2}$ & 232 & 18,54 & 7,00 & & \\
\hline Toplam puan & $20-24,99 \mathrm{~kg} / \mathrm{m}^{2}$ & 230 & 66,75 & 26,50 & $-1,19$ & 0,234 \\
\cline { 2 - 5 } & $25-38 \mathrm{~kg} / \mathrm{m}^{2}$ & 232 & 69,62 & 25,29 & & \\
\hline
\end{tabular}

$\mathrm{p}>0,05$

Beden kütle indeksi kategorisine göre boş zaman stratejisi alt ölçek ve toplam puanları karşılaştırılmasında önemli bir farklılık tespiti bulunmamıştır $(\mathrm{p}>0,05)$.

Tablo 5: Gelir durumuna göre boş zaman stratejisi puanlarının karşılaştırılması

\begin{tabular}{|c|c|c|c|c|c|c|}
\hline$n=462$ & Gelir Düzeyi & $\mathbf{N}$ & Ort. & SS & F/LSD & p \\
\hline \multirow[t]{5}{*}{ Arkadaşlik } & Düşük gelir (1) & 76 & 22,91 & 9,36 & \multirow{5}{*}{$\begin{array}{l}3,04^{*} \\
3>2,4\end{array}$} & \multirow[t]{5}{*}{0,029} \\
\hline & Orta seviye (2) & 152 & 21,95 & 9,53 & & \\
\hline & İyi durum (3) & 133 & 24,99 & 8,43 & & \\
\hline & Çok iyi durum (4) & 101 & 22,39 & 8,39 & & \\
\hline & Toplam & 462 & 23,08 & 9,01 & & \\
\hline \multirow{5}{*}{$\begin{array}{l}\text { Geçici baş } \\
\text { edebilme }\end{array}$} & Düșük gelir (1) & 76 & 24,81 & 10,83 & \multirow{5}{*}{$\begin{array}{l}4,31 * \\
1<3,4\end{array}$} & \multirow[t]{5}{*}{0,005} \\
\hline & Orta seviye (2) & 152 & 26,83 & 10,62 & & \\
\hline & İyi durum (3) & 133 & 29,05 & 9,44 & & \\
\hline & Çok iyi durum (4) & 101 & 27,41 & 9,29 & & \\
\hline & Toplam & 462 & 26,93 & 10,15 & & \\
\hline \multirow{5}{*}{$\begin{array}{l}\text { Ruh hali } \\
\text { iyileştirme }\end{array}$} & Düşük gelir (1) & 76 & 17,31 & 7,68 & \multirow{5}{*}{$\begin{array}{l}4,96 * \\
3>1,2\end{array}$} & \multirow[t]{5}{*}{0,002} \\
\hline & Orta seviye (2) & 152 & 17,05 & 7,38 & & \\
\hline & İyi durum (3) & 133 & 20,09 & 6,57 & & \\
\hline & Çok iyi durum (4) & 101 & 18,25 & 7,03 & & \\
\hline & Toplam & 462 & 18,18 & 7,22 & & \\
\hline \multirow{5}{*}{$\begin{array}{l}\text { Toplam } \\
\text { puan }\end{array}$} & Düşük gelir (1) & 76 & 63,82 & 27,61 & \multirow{5}{*}{$\begin{array}{l}3,91 * \\
3>1,4\end{array}$} & \multirow[t]{5}{*}{0,009} \\
\hline & Orta seviye (2) & 152 & 67,99 & 27,22 & & \\
\hline & İyi durum (3) & 133 & 74,13 & 24,02 & & \\
\hline & Çok iyi durum (4) & 101 & 67,10 & 23,78 & & \\
\hline & Toplam & 462 & 68,19 & 25,91 & & \\
\hline
\end{tabular}

Gelir durumuna göre boş zaman stratejisi alt ölçek ve toplam puanları karşılaştırılmasında gelir derecesi iyi olanların puanı gelir derecesi düşük ve çok iyi olanlardan önemli derecede yüksek bulunmuştur $(\mathrm{p}<0,05)$. LSD testi sonuçlarına göre; boş zaman yolu ile stresle baş etme strateji ölçeği arkadaşlık alt boyutunda gelir düzeyi iyi olanların ortalamaları, orta ve çok iyi gelir düzeyine sahip olanların ortalamalarından anlamlı şekilde yüksek bulunmuştur. Geçici baş edebilme alt boyutunda; düşük gelir düzeyine sahip olanların ortalaması, iyi ve çok iyi gelire sahip olanların ortalamasından anlamlı şekilde düşüktür. Ruh halini iyileştirme alt boyutunda; gelir düzeyi iyi durumda olanların ortalaması, düşük ve orta gelire sahip olanların ortalamasından yüksektir. Toplam puan incelendiğinde ise; gelir durumu iyi olan kişilerin ortalaması, düşük ve çok iyi gelir düzeyine sahip olanların ortalamasından anlamlı şekilde yüksek olduğu tespit edilmiştir.

Tablo 6: Medeni durumuna göre boș zaman stratejisi puanlarının karșılaştırılması

\begin{tabular}{|c|c|c|c|c|c|c|}
\hline$n=462$ & Medeni durum & $\mathbf{N}$ & Ort. & SS & t- tosti & p \\
\hline \multirow[t]{2}{*}{ Arkadaşlık } & Evli & 291 & 22,19 & 9,07 & \multirow[t]{2}{*}{$-2,80^{*}$} & \multirow[t]{2}{*}{0,005} \\
\hline & Bekar & 171 & 24,60 & 8,73 & & \\
\hline \multirow{2}{*}{$\begin{array}{l}\text { Geçici baş } \\
\text { edebilme }\end{array}$} & Evli & 291 & 26,09 & 10,26 & \multirow[t]{2}{*}{$-2,33^{*}$} & \multirow[t]{2}{*}{0,020} \\
\hline & Bekar & 171 & 28,36 & 9,82 & & \\
\hline \multirow{2}{*}{$\begin{array}{l}\text { Ruh hali } \\
\text { iyileştirme }\end{array}$} & Evli & 291 & 17,67 & 7,06 & \multirow[t]{2}{*}{$-1,98^{*}$} & \multirow[t]{2}{*}{0,048} \\
\hline & Bekar & 171 & 19,05 & 7,43 & & \\
\hline Toplam puan & Evli & 291 & 65,95 & 26,14 & $-2,44^{*}$ & 0,015 \\
\hline
\end{tabular}




\begin{tabular}{lllll}
\hline & Bekar & 171 & 72,01 & 25,12 \\
\hline * $\mathbf{p}<\mathbf{0 , 0 5}$ & & &
\end{tabular}

Medeni duruma göre boş zaman stratejisi alt ölçek ve toplam puanları karşılaştırıldığında; toplam puanı bekar olanların evli olanlardan anlamlı derecede yüksek bulunmuştur $(p<0,05)$. Boş zaman yolu ile stresle baş etme strateji ölçeği, arkadaşl1k, geçici baş edebilme, ruh hali iyileştirme alt boyutları ile toplam puanda medeni durum değişkenine göre bekar kişiler lehinde anlamlı bir farkl11ık görülmektedir.

\section{Tartışma ve Sonuç}

Rekreatif amaçlı olarak halı sahalarda futbol oynayanların serbest zaman yolu ile stresle baş edebilme stratejilerinin incelenmesinin amaçlandığ yorumlanmıştır.

Çalışmaya katılanların yaş kategorisine göre boy uzunlukları ortalamaları 173,09-175,06 cm arasında değişmektedir. Vücut ağırlıkları ortalamaları ise 73,72 -79,37 kg arasındadır. Beden kütle indeks değerleri ise $24,57-25,91 \mathrm{~kg} / \mathrm{m}^{2}$ olarak bulunmuştur. Boy uzunlukları, vücut ağırlıkları ve beden kütle indeksleri arasında yaş gruplarına göre anlamlı farklılık tespit edilmiştir $(p<0,05)$. LSD testi sonuçlarına göre; boş zaman yolu ile stresle baş etme strateji ölçeği vücut ağırlığında 30-35 yaşın ortalaması 20-24 ile 25-29 yaşın ortalamalarından anlamlı şekilde yüksek bulunmuştur. Ayrıca beden kütle indeksi değerinde 30-35 yaşın ortalamasının 20-24 yaşın ortalamasından anlamlı şekilde yüksek olduğu tespit edilmiştir. Yaş kategorisi arttıkça vücut ağırlığının da arttığ1 görülmektedir. Beden kütle indeks değerleri $24-26,9 \mathrm{~kg} / \mathrm{m}^{2}$ ve üzeri ise insanlar kilolu kabul edilir (Hsu ve diğ., 2018). Bu çalışmaya katılanlar kilolu olarak kabul edilebilirler. Genel olarak, vücut kitle indeksi 25 $\mathrm{kg} / \mathrm{m}^{2}$ ise herkes sağlıklı ve $25 \mathrm{~kg} / \mathrm{m}^{2}$ sonraki durumda ise hasta olarak kabul edilir (Turgut ve diğ., 2018). Ancak bu sinıflandırma sedanter insanlar içindir. Fakat İmamoğlu ve diğ. (2010) çalışmasında, sporcular için beden kütle indeksinin $25 \mathrm{~kg} / \mathrm{m}^{21}$ de normal olduğunu bildirmiştir. $\mathrm{Bu}$ çalışmada 30-35 yaş grubunun vücut ağırlıklarının normal sınırların üzerinde olduğu görülmüştür.

Bedir (2016) çalışmasında arkadaşlık alt boyutunu ortalamasını 5,93 puan; geçici baş etme alt boyutunu ortalamasinı 5,53 puan; ruh hali artırma alt boyutunu ortalamasinı 6,14 puan ve toplam ortalamay 15,87 puan olarak bulmuştur. Bu çalışmada arkadaşlık alt boyutunun puan ortalaması 23,08 puan; geçici baş edebilme alt boyutunun puan ortalaması 29,36 puan; ruh hali artırma alt boyutunun puan ortalamas1 18,10 puan ve toplam puan ortalaması ise 68,19 puan olarak tespit edilmiştir. İki araştırmadan elde edilen ortalama puanlar, soru sayıları ve denekler farklı olduğu için değişkenlik göstermektedir.

Coleman ve Iso-Ahola (1993)'nın yapmış olduğu çalışmada sosyal aktiviteler yoluyla kazanılmış arkadaşlıkların yalnızlık ve toplumdan soyutlanma duygusunu azaltma ve insanlara sosyal destek kazandırma durumuna sahip olduğu belirtilmiştir. Kır (2007) yaptığı çalışmada gençliğin serbest zamanlarını değerlendirme konusunda üst düzeyde bir duyarlılık sergilemediklerini belirtmiştir. Yine pasif/edilgen etkinlikler içerisine girdikleri ve boş zamanı geçirmenin onlara sunulan imkânlarla sınırlı bir durum gösterdiğini belirtmiştir. Uzun ve diğg. (2017) çalışmalarında lise öğrencilerinde yaş grubuna göre bireysel psikoloji alt boyutunda anlamlı bir farklılık belirtmişlerdir. Demirtaş ve İmamoğlu (2018) çalışmalarında öğrencilerin boş zaman engelleri konusundaki algılarının yaş, eğitim görülen bilim alanı ve rekreatif faaliyetlere katılıma göre değiştiğini; ancak sınıf ve gelir seviyesine göre değişmediğini belirtmişlerdir. Yine spor yapanların stres seviyelerinin düştügü̈ belirtilmiştir (Deryahanoğlu ve diğ., 2016; Çiçek ve diğ., 2017). Yener (2020) çalışmasında boş zaman stratejisi alt ölçeklerini yaş kategorisi kapsamında incelemiştir. Bu bağlamda Yener tarafından incelenen çalışmanın bulgularına göre; arkadaşlık, geçici baş edebilme, ruh hali ve toplam puanda istatistiksel olarak fark anlamlı bulunmuştur. Bizim yaptığımız çalışmada yaş kategorisine göre boş zaman stratejisi alt ölçekler ve toplam puanda istatistiksel olarak anlamlı bir farklılık tespit edilmiştir $(p<0,05)$. Üçüncü yaş kategorisindekilerin puanları daha düşüktür. Boş zaman 
arkadaşlığında, geçici baş edebilme ve ruh halini iyileştirme durumunda 20-24 ve 25-29 yaş grupları puanlarının 30-35 yaş grubu puanlarına göre daha yüksek olduğu görülmektedir.

Geçmişinde aktif spor yapma durumuna göre boş zaman stratejisi alt ölçek ve toplam puanları karşılaştırılmasında alt ölçeklerde ve toplam puanda istatistiksel olarak anlamlı farklılık bulunmamıştır $(\mathrm{p}>0,05)$. Geçmişinde aktif spor yapma durumuna göre boş zaman stratejisi alt ölçek ve toplam puanları karşılaştırılmasında alt ölçekler ve toplam ölçekte istatistiksel olarak önemli bir farklılık görülmese de geçmişte spor yapanların puanları daha yüksektir. Spor ile kazanılmış bazı olumlu özelliklerin (arkadaşlık gelişimi, anksiyete ve stresten uzaklaşma vs.) uzun dönemde de etkisini gösterdiği düşünülebilir. Spor yapan insanların spor yapmayan fertlere göre çok daha cana yakın, dışa dönük kişilik, daha çok çalışama yeterli, daha fazla sabırlı, toplumsal ilişkileri kurma konusunda daha iyi durumda, yeni bir konuma uyum sağlamada daha iyi ve psikolojik olarak daha dengeli kişiliğe sahip oldukları ileri sürülür (Yamak ve İmamoğlu, 2019).

İnsanların vücut dış görüntülerinden memnun olmaları olumlu düşünmelerine neden olabilir (Yamak ve diğ., 2018). Fakat bu çalışmada beden kütle indeksine göre normal sağlıklı olma sınırları içerisinde bulunanlar ile obez bulunanların ölçek puanlarında istatistiksel olarak anlamlı farklılık bulunmamıştır $(p>0,05)$. Vücut ağırlı̆̆ına göre sağlıklı ve obez olma durumunun boş zaman yolu ile stresle baş etme stratejisi konusunda bir etkisi olmadığ düşünülmektedir.

Psikolojik sermaye düzeyleri yüksek olan insanların stres ortaya çıktığında onlarla mücadele konusunda kendilerini daha yetkin görürler (Kodaş, 2018). Bedir (2016) çalışmasında spor bilimleri fakültesinde öğrenin gören öğrencilerin aylık gelirleri ile boş zaman strateji alt boyut puanları ve toplam puanları arasında da anlamlı farklılık bulmamıştır. Yener (2020) fitness merkezlerine spor yapma amaçlı gidenlerin boş zaman yolu ile stresle baş edebilme stratejilerinin gelir duruma göre değiştiğini bulmuştur. Bu çalışmada gelir durumuna göre boş zaman stratejisi alt ölçek ve toplam puanları karşılaştırılmasında tüm alt ölçeklerde ve toplam ölçek puanda anlamlı farklılık bulunmuştur $(\mathrm{p}<0,05)$. LSD testi sonuçlarına göre; boş zaman yolu ile stresle baş etme strateji ölçeği arkadaşlık alt boyutunda gelir düzeyi iyi olanların ortalamaları, orta ve çok iyi gelir düzeyine sahip olanların ortalamalarından anlamlı şekilde yüksek bulunmuştur. Geçici baş edebilme alt boyutunda; düşük gelir düzeyine sahip olanların ortalaması, iyi ve çok iyi gelire sahip olanların ortalamasından anlamlı şekilde düşüktür. Ruh halini iyileştirme alt boyutunda; gelir düzeyi iyi durumda olanların ortalaması, düşük ve orta gelire sahip olanların ortalamasından yüksektir. Toplam puan incelendiğinde ise; gelir durumu iyi olan kişilerin ortalaması, düşük ve çok iyi gelir düzeyine sahip olanların ortalamasından anlamlı şekilde yüksek olduğu tespit edilmiştir. Gelir durumu iyi olanların boş zaman yolu ile stresle baş edebilme stratejilerinin daha iyi olduğu düşünülmektedir.

Medeni duruma göre boş zaman stratejisi alt ölçek ve toplam puanları karşılaştırılmasında alt ölçek ve toplam ölçek puanları arasında istatistiksel olarak anlamlı farklılık bulunmuştur $(p<0,05)$. Boş zaman yolu ile stresle baş etme strateji ölçeği, arkadaşlık, geçici baş edebilme, ruh hali iyileştirme alt boyutları ile toplam puanda medeni durum değişkenine göre bekar kişiler lehinde anlamlı bir farklılık görülmektedir. Bekar olanların evli olanlara göre puanları daha yüksektir. Bu durum evli olanların ailelerine karşı sorumluluk hissetmelerine de bağlanabilir.

Çalışma bulguları 1şığında; halı sahalarda futbol oynayanların boş zaman yolu ile stresle baş edebilme stratejileri yaş kategori, gelir ve medeni duruma göre değiştiği ve vücut ağırlığına göre ise değişmediği sonucuna varılmıştır. Halı sahalarda futbol oynayanlara boş zaman yolu ile stresle baş edebilme ve ruh halini iyileştirebilme konularında açıklayıcı bilgiler verilebilir. 


\section{Kaynakça}

Ağılönü, A. (2007). Yerel yönetimlerde rekreasyon hizmetleri ve model belirleme: Fethiye örneği. Yayınlanmamış doktora tezi, Marmara Üniversitesi Sağlık Bilimleri Enstitüsü.

Aksoy, Y. (2020). Fitness merkezlerine giden insanların boş zaman stratejilerinin incelenmesi. Atatürk Üniversitesi Beden Eğitimi ve Spor Bilimleri Dergisi, 22(1), 55-63.

Alay, S., Koçak, S. (2003). Üniversite öğrencilerinin zaman yönetimleri ile akademik başarıları arasındaki ilişki. Kavram ve Uygulamada Eğitim Yönetimi Dergisi, 9(3), 326- 335.

Aldwin, C. M. (2014). Stress, Coping, and Development: An Integrative Perspective. Guilford Publications.

Atan, T., Tural, E., Imamoglu, O., Çiçek, G., Tural, S. (2012). Physical activity levels of teachers and health professionals in Turkey. HealthMED, 6(6), 1935-1942.

Atan, T., Eliöz, M., Çebi, M., Ünver, Ş., Atan, A. (2016). Basketbol Antrenmanın Eğitilebilir Zihinsel Engelli Çocukların Motorik Özelliklerine Etkisinin İncelenmesi. Journal of Sports and Performance Researches, 7(1) 29-35.

Ayyıldız, E., Sunay, H., Köse, B., \& Atlı, A. (2019). Investigation of the life quality of women in Ankara according to their participation in physical activity. Acta Medica Mediterranea, 35, 3427-3431.

Bedir, F. (2016). Boş Zaman (Rekreasyonel) Aktivitelerinin Stresin Üstesinden Gelebilme Rolünün İncelenmesi. Yüksek lisans tezi, Atatürk Üniversitesi Sosyal Bilimler Enstitüsü.

Bedir, F., Bedir, D., Erhan, S. E., Şen, İ. (2016). Boş Zaman Stres ile Başa Çıkma İnanış Ölçeğinin Türkçe Geçerlik Güvenirlik Çalışması. Atatürk Üniversitesi Beden Eğitimi ve Spor Bilimleri Dergisi, 18(4), 9-16.

Coleman, D., Iso-Ahola, S. E. (1993). Leisure and Health: The Role of Social Support and Selfdetermination. Journal of Leisure Research, 25, 111-128.

Davis, R. J., Bull, C. R., Roscoe, J. V., Rocoe, D. A. (1991). Physical Education and The Study of Sport. Wolf Publishing.

Doğan Laçin, B. G., Yalçın, İ. (2019). Üniversite öğrencilerinde öz-yeterlilik ve stresle başa çıkma stratejilerinin bilişsel esnekliği yordama düzeyleri. Hacettepe Üniversitesi Ĕ̈itim Fakültesi Dergisi, 34(2), 358-371. doi: 10.16986/HUJE.2018037424

Çevik, H., Özcan, Ö., Munusturlar, S. (2018). Boş Zaman Yoluyla Stresle Baş Etme İnancı Ölçeği ve Boş Zaman Yoluyla Stresle Baş Etme Strateji Ölçeğinin Faktör Yapısının Türkiye Örneklemine Yönelik Sınanması: Geçerlik ve Güvenirlik Çalışması. SPORMETRE, 17(2), 36-50.

Çiçek, G., İmamoğlu, O., Yamaner, F., Türk, N. (2017). Psychological Effects of Cardio Bosu Exercise on Sedentary Women. International Journal of Sports, Exercise and Training Science, 3(3), 69-75.

Demirtaş, Ö., İmamoğlu, G. (2018). Spor ve Sanat Eğitimi Alan Üniversite Öğrencilerde Boş Zaman Engellerinin Araştırılması, Herkes İçin Spor ve Wellness Araştırmaları, (Editörler: M. Ali Öztürk, Süleyman Gönülateş). Akademisyen Kitabevi, 369-381.

Deryahanoğlu, G., İmamoğlu, O., Yamaner, F., Uzun, M. (2016). Anthropometric characteristics of sedentary women and comparison of their psychological states. Journal of Human Sciences, 13(3), 5257-5268. 
Endler, N. S., Parker, J. D. A. (1990). Coping Inventory for Stressful Situations: Manual. MultiHealth Systems.

Folkman, S., Moskowitz, T. Judith, (2004), "Coping: Pitfalls and Promise", Annual Review of Psychology, Vol.55, 1, pp.745-74

Goodman, F. R., Kashdan, T. B., İmamoğlu, A. (2020). Valuing Emotional Control in Social Anxiety Disorder: A Multimethod Study of Emotion Beliefs and Emotion Regulation. Emotion. Advance online publication. DOI: http://dx.doi.org/10.1037/emo0000750

Gülbahçe, Ö. (1996). Boş Zamanlarını Değerlendirme Alışkanlıkları. Yayınlanmamış Yüksek lisans tezi, Atatürk Üniversitesi Sosyal Bilimler Enstitüsü.

Hsu, C. C., Wahlqvist, M. L., Wu, I. C., Chang, Y. H., Chang, I. S., Tsai, Y. F., Hsiung, C. A. (2018). Cardiometabolic disorder reduces survival prospects more than suboptimal body mass index irrespective of age or gender: a longitudinal study of 377,929 adults in Taiwan. BMC Public Health, 18(1), 142.

Iwasaki, Y., Mannell, R. C. (1999). The Effects of Leisure Beliefs and Coping Strategies On StressHealth Relationships: A Field Study. Leisure/Loisir, 24(1-2), 3-57.

Iwasaki, Y. (2006). Counteracting stress through leisure coping: A prospective health study. Psychology, Health \& Medicine, 11(2), 209-220.

Iwasaki, Y., MacKay, K., Mactavish, J. (2005). Gender-based analogues of coping with stress among professional managers: Leisure coping and non-leisure coping. Journal of Leisure Research, $37(1), 1-28$.

İmamoğlu, O., Ağaoğlu, Y. S., Eker, H. (2010). The investigation of nutritional habits of department of physical education and sports students in different cities. Journal of Physical Education and Sport Science, 12(4), 1-12.

Kabadayı, M., Eski, T., Bayram, L., Yılmaz, A. K., Mayda, M. H. (2017). Analysis of the Factors which Influence Participation of University Students in Recreational Activities. European Journal of Education Studies, 3(12), 161-171.

Karaküçük, S. (2014). Rekreasyon: Boş Zamanları Değerlendirme. 7. Baskı, Gazi Kitabevi.

Kaya, S. (2003). Yetiştirme yurtlarında kalan gençlerin boş zaman değerlendirme eğilimi ve etkinliklerin sosyalleşmeye etkisi. Yayınlanmamış Doktora tezi, Gazi Üniversitesi Sağlık Bilimleri Enstitüsü.

Kılbaş, Ş. (1995). Gençlik ve Boş Zamanı Değerlendirme. Çukurova Üniversitesi Basımevi.

Kır, İ. (2007). Yüksek Öğretim Gençliğinin Boş Zaman Etkinlikleri: KSÜ Örneği. Fırat Üniversitesi Sosyal Bilimler Dergisi, 17(2), 307-328.

Kırtepe, A., Uğurlu, M. F. (2018). Determination of the Leisure Time Management of Individuals who Go to Gym for Recreation Purposes, According to Distinctive Variables. Turkish Studies, 13(3), 783-792. DOI: http://dx.doi.org/10.7827/TurkishStudies.13146

Kızıldağ, D. (2018). Çalışan Stresi, Olumsuz İş̧ Gören Tutumları ve Davranışları, Özkara, B. (Ed.) Endüstri ve Örgüt Psikolojisine Giriş İçinde. İskitler, Nobel Yayın.

Koca, F., İmamoğlu, G., İmamoğlu, O. (2018). Sports Status of High School Students and Investigation of Personality Characteristics by Gender. The Journal of Academic Social Science, 80, 31-42. 
Kodaş, B. (2018). Psikolojik Sermaye, İş Stresi ve Hizmet Odaklı Örgütsel Vatandaşlık Davranışı İlişkisi: Yiyecek İ̧̧ecek Çalışanları Örneği. Doktora tezi, Eskişehir Osmangazi Üniversitesi Sosyal Bilimler Enstitüsü.

Shields, M. (2003). Stress, health and the benefit of social support. Health Reports, Catalogue, No. 82-003-XPE, 15(1), Statistics Canada.

Taşmektepligil, M. Y., Ağaoğlu, S. A., Atan, T., Çiçek, G. (2013). The contrastive study of physical activity levels of phsical education students and the other department students. International Journal of Academic Research Part A, 5(6), 90-95. DOI: 10.7813/2075-4124.2013/5-6/A.12

Tolukan, E. (2010). Özel Yetenekle Illgili Bölümlerde Okuyan Üniversite Öğrencilerinin Rekreasyonel Aktivitelere Katılımlarına Engel Olabilecek Unsurların Belirlenmesi. Yüksek lisans tezi, Niğde Üniversitesi Sosyal Bilimler Enstitüsü.

Turgut, M., Akbulut, T., İmamoğlu, O., Çınar, V. (2018). The Effect of 3 Month Cardio Bosu Exercises on Some Motoric, Physical and Physiological Parameters in Sedentary Women. Sp Soc Int J Ph Ed Sp, 18(2), 48-52.

Uzun, M., İmamoğlu, O., Yamaner, F., Deryahanoğlu, G., Yamaner, G. (2017). Rekreatif etkinliklere katılımı engelleyen faktörlerin incelenmesi: Kız lisesi örneği. Journal of Human Sciences, 14(1), 950-962. DOI: 10.14687/jhs.v14i1.4174

Yamak, B., İmamoğlu, O. (2019). The Beck Hopelessness Level According to Behavior Change Stages in University Ondokuz Mayis Students. Turkish Studies Educational Sciences, 14(3), 937-947. DOI: 10.29228/TurkishStudies.22941

Yamak, B., İmamoğlu, O., İslamoğlu, İ., Çebi, M. (2018). The Effects of Exercise on Body Posture. Turkish Studies Social Sciences, 13(18), 1377-1388, DOI: http://dx.doi.org/10.7827/TurkishStudies.13911 